\title{
ANÁLISIS Y PLANIFICACIÓN DE ZONAS INUNDABLES ESTUDIO DE CASO: QUEBRADA Y CANAL DE RAMÓN, SANTIAGO DE CHILE
}

\author{
J. Cadierno Gutiérrez \\ Universidad del País Vasco/ Euskal Herriko Unibertsitatea \\ Paseo de la Universidad, 5. 01006 Vitoria-Gasteiz, Álava \\ joncadierno@gmail.com
}

\begin{abstract}
Resumen: El presente trabajo aborda el análisis y la planificación de una zona inundable en Santiago de Chile afectada por los desbordamientos de la Quebrada de Ramón. A partir del análisis del marco normativo vigente sobre áreas inundables, la elaboración de diagnósticos acerca del comportamiento de caudales y la evaluación del cumplimiento de la normativa y la adecuación de los usos del suelo dentro de las zonas de restricción delimitadas por los planes reguladores, se presenta una serie de propuestas para la elaboración de una nueva planificación de zonas inundables. La base de estas alternativas es la recuperación parcial del Territorio Fluvial, proponiéndose así soluciones desde la ordenación del territorio que mitiguen el riesgo de la población expuesta, principalmente a través de la eliminación de obstáculos para permitir a las crecidas re-ocupar áreas que pertenecen a la dinámica fluvial.
\end{abstract}

Palabras clave: zonas inundables, planificación territorial, Territorio Fluvial, Quebrada de Ramón, Santiago de Chile.

\begin{abstract}
The present work addresses the analysis and planning of an area affected by the floods of Ramon's Stream, in Santiago de Chile. From the analysis of the current normative framework about flood zones, the elaboration of a diagnosis about the flow behaviour and the evaluation of the law compliance and the adaptation of the soil uses in the restricted areas demarcated by the land management plans, a series of suggestions for the elaboration of a new planning for flood zones is presented. The basis of these
\end{abstract}

Recibido: 13-11-14. Aceptado: 5-12-14. 
alternatives is the partial recovery of the River Territory, thus suggesting some solutions coming from land management which reduce the risk of the exposed population, mainly through the elimination of obstacles in order to let the swellings re-occupy the areas that belong to the river dynamics.

Keywords: flood zones, land management, River Territory, Ramon's Stream, Santiago de Chile.

\section{Introducción}

Primeramente, debe especificarse que el presente trabajo es una adaptación del Trabajo de Fin de Grado presentado por el autor bajo el mismo título, en julio del 2014, como requisito indispensable para optar al título de Graduado en Geografía y Ordenación del Territorio por la Universidad del País Vasco/ Euskal Herriko Unibertsitatea.

Dirigiendo la atención a la zona de estudio, la Quebrada de Ramón, una cuenca hidrográfica situada en el Sector Oriente de la ciudad de Santiago de Chile, en la zona central del país, ha provocado múltiples eventos de inundaciones en los últimos años a su paso por La Reina, una municipalidad ubicada en el sector oriental del Gran Santiago.

El origen de este problema tiene dos explicaciones principales: una natural, relacionada con las características climáticas de la zona central de Chile, donde tras un periodo seco de siete u ocho meses pueden registrarse precipitaciones invernales torrenciales. A esto habría que sumarle el efecto orográfico de la cordillera de los Andes, el fuerte desnivel de la cuenca y la posición del municipio al pie de un abanico aluvial; por otro lado, están las causas antrópicas relacionadas con un fuerte crecimiento urbano ligado a la liberalización del suelo, consecuencia directa de la Política Nacional de Desarrollo Urbano de 1979 que, por lo general, se realizó sin un control para la correcta gestión de las aguas de lluvia, lo que aumentó notablemente la extensión de las áreas urbanizadas e impermeables.

\section{Antecedentes y estado de la cuestión}

La Quebrada de Ramón ha provocado múltiples eventos de inundaciones en los últimos años a su paso por el municipio de La Reina. Algunos claros ejemplos de ello son los flujos de detritos de las quebradas de San Ramón y Macul del 3 de mayo de 1993 -que causaron 30 muertos y serios daños materiales (Naranjo y Varela, 1996)-, y una serie de eventos menores registrados en el área de estudio durante los últimos 25 años (García, 2000; Padilla, 2006), entre los que se encuentran las graves inundaciones que afectaron a la capital en junio del 2002 y el desbordamiento del canal en agosto del 2005 o mayo del 2008, entre otros. 
Pese a la realización de una importante obra de ensanchamiento del canal en 2010, su eficacia aún debe ser comprobada, pues todo apunta a que la nueva capacidad del conducto sigue sin ser suficiente. Por otro lado, hay una clara necesidad de avanzar en materia de planificación urbana ligada a zonas inundables, ya que la problemática no se aborda correctamente ni en los planes reguladores ni en el resto del marco normativo existente.

\section{Metodología}

La base de la metodología empleada ha consistido en una revisión bibliográfica de la normativa actual sobre zonas inundables, la documentación sobre el ámbito de estudio y las capas de información cartográfica. Todo ello ha permitido elaborar análisis y diagnósticos sobre dicha normativa, principalmente centrada en los planes reguladores metropolitanos y locales, que han sido complementados con análisis y diagnósticos sobre los datos aportados por la estación de aforo- junto con un estudio de su comportamiento medio y extremo mediante ajustes estadísticos- y sobre los datos de precipitación obtenidos de la estación meteorológica, así como su relación con los datos de caudal. Las conclusiones extraídas a partir de la evaluación de las características de estos fenómenos han conllevado la aplicación al área de estudio de propuestas de delimitación de zonas inundables como el Territorio Fluvial, que ha permitido la presentación de alternativas para una nueva planificación de estas zonas, siendo esta una medida que "permite una mejor urbanización y/o la mitigación de los daños provocados en la población y su entorno" (Lara Castillo, 2007, pág. 2).

Las principales bases de datos utilizadas han sido las de la Dirección General de Aguas (caudal y precipitaciones), el Censo del 2002 (población), el Centro de Inteligencia Territorial de la Universidad Adolfo Ibáñez (capas de información cartográfica) y las municipalidades de Las Condes y La Reina. Por otro lado, el conjunto del análisis, diagnóstico y propuestas ha conllevado la elaboración de cartografía realizada mediante herramientas SIG (ArcGIS 10.1).

\section{Marco geográfico del área de estudio}

La Quebrada de Ramón está situada en la falda de la cordillera de los Andes en la zona central de Chile (fig. 1), concretamente al oriente de la ciudad capital del país, Santiago de Chile (fig. 2). Nace en el Cerro San Ramón (3.254 m.s.n.m.), al este de la ciudad (fig. 3), desciende hacia el valle siguiendo un sentido general S-N en su tramo superior, para girar hacia el oeste en su tramo medio, justo después de recibir las aguas de la Quebrada La Pichoca. En este descenso por la cordillera y hasta penetrar en la 
ciudad de Santiago, la Quebrada de Ramón recibe el aporte de numerosas quebradas tributarias que forman parte de la cuenca. En orden descendente en altura, las más importantes son la Quebrada Los Maquis, La Pichoca, numerosas quebradas que descienden de los cerros La Provincia y Alto Las Vizcachas y la Quebrada Quillayes, tal y como se muestra en la figura 2. La Quebrada de Ramón tiene una longitud aproximada de $11 \mathrm{~km}$ y su cuenca ocupa un área cercana a los $64 \mathrm{~km}^{2}$.

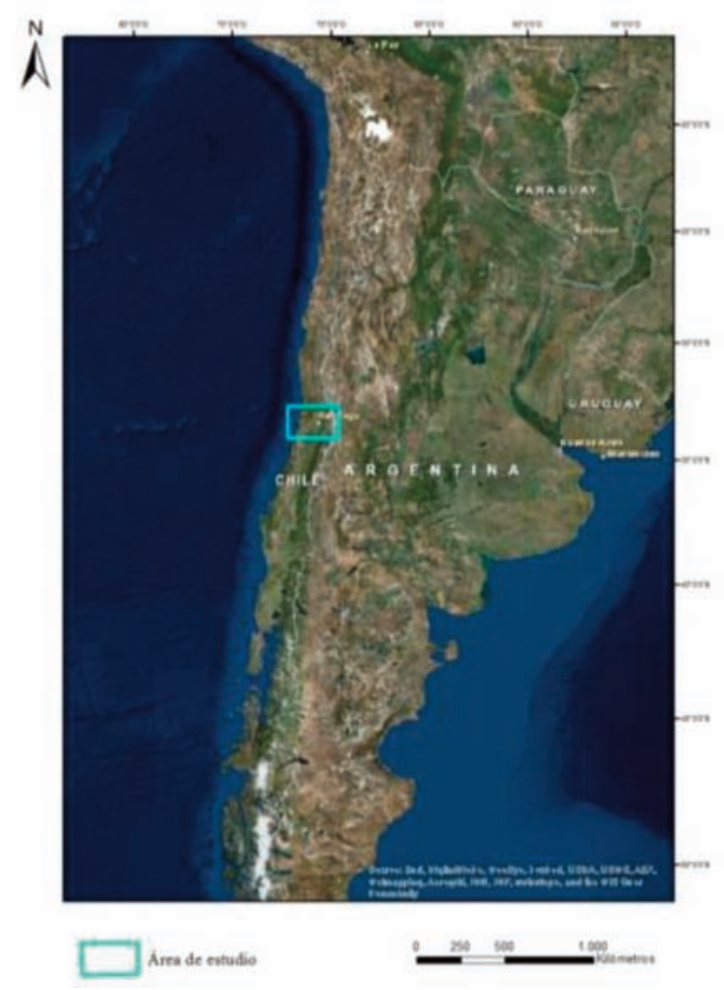

Figura 1. Mapa de situación del área de estudio en su contexto regional.

Fuente: Elaboración propia.

Unos dos kilómetros después de adentrarse en el valle de Santiago y dejar atrás los cerros que la encajonaban, la Quebrada de Ramón pasa por debajo del Canal Las Perdices, también artificial, que nace en el sureste de la ciudad y lleva un sentido general S-N. Finalmente, está el Canal San Carlos, donde desemboca la Quebrada de Ramón ya convertida en canal artificial. El Canal San Carlos trasvasa las aguas del río Maipo también desde el sureste de la ciudad y sigue un rumbo SE-NO hasta verter sus aguas en el río Mapocho después de atravesar la zona oriental de Santiago de Chile. 


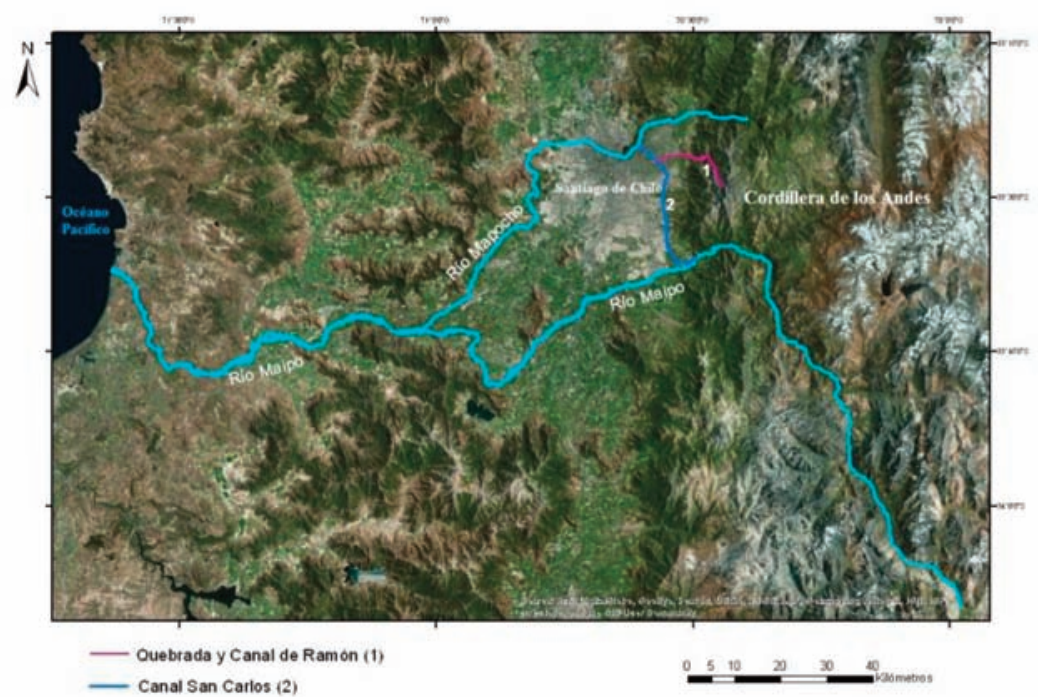

Figura 2. Situación de la Quebrada de Ramón y la red fluvial principal de la Región Metropolitana de Santiago.

Fuente: Elaboración propia a partir de la información proporcionada por el Centro de Inteligencia Territorial (CIT) de la Universidad Adolfo Ibáñez (UAI) (2011).

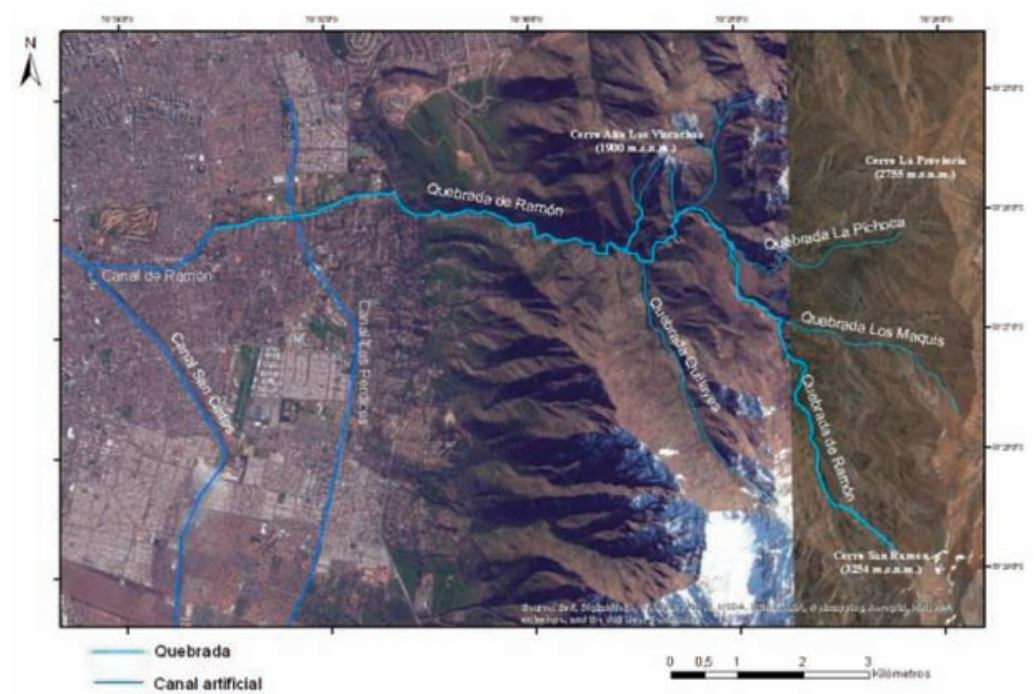

Figura 3. Red de drenaje de la Quebrada de Ramón.

Fuente: Elaboración propia a partir de la información proporcionada por el CIT de la UAI (2011). 
En lo relativo a las modificaciones de su cauce en el área urbana, es encauzada aguas abajo del puente de la Avenida Padre Hurtado, que es el punto de cruce con el Canal Las Perdices (fig. 4), cuando discurre entre muros laterales y numerosas piscinas de decantación. El nombre de Canal San Ramón lo adquiere aguas abajo del puente de la calle Florencio Barrios, y desde aquí hasta su desembocadura en el Canal San Carlos, el canal artificial atraviesa una zona preferentemente residencial, discurriendo muchas veces por la parte trasera de viviendas generalmente unifamiliares.

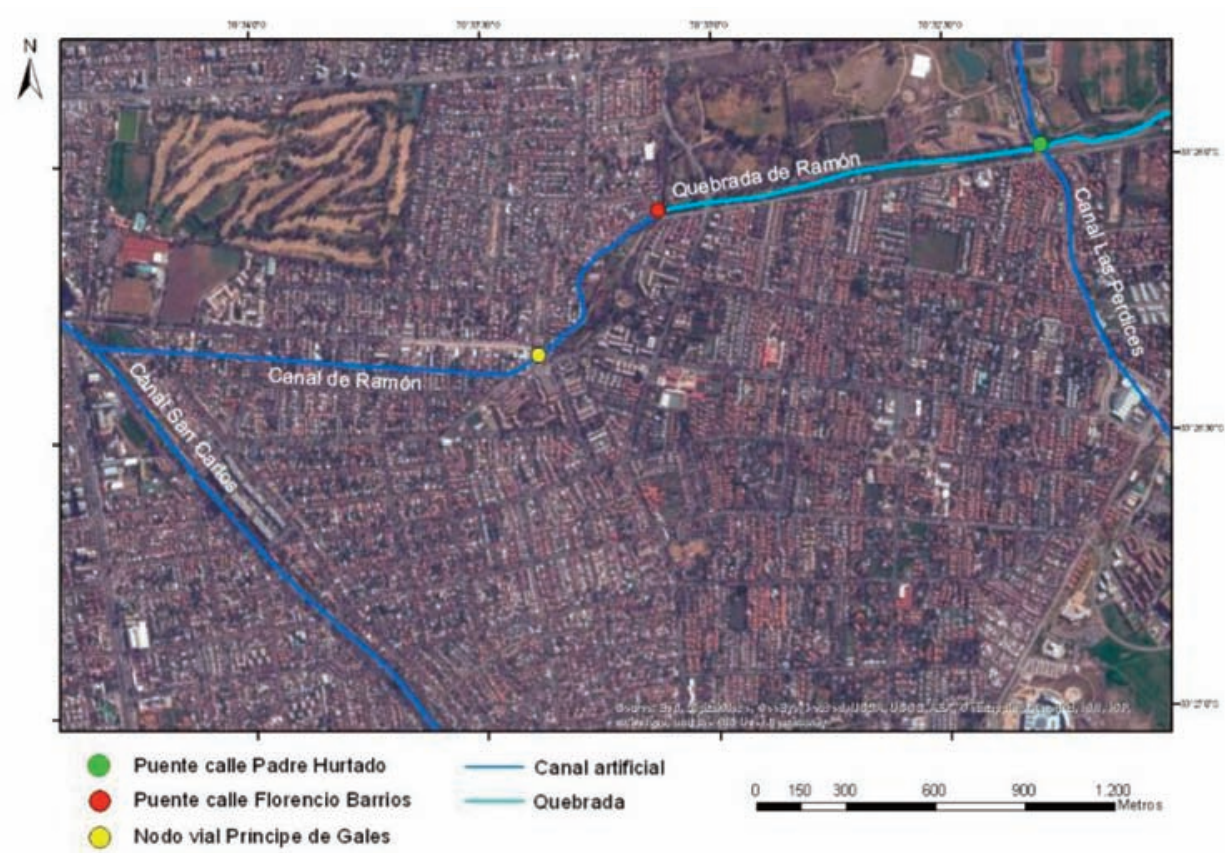

Figura 4. Puntos clave del tramo urbano de la Quebrada y el Canal de Ramón.

Fuente: Elaboración propia.

\subsection{Marco tectónico, geología y geomorfología}

La Quebrada de Ramón nace en la Cordillera de los Andes y desemboca en el Canal San Carlos en la depresión intermedia, lo que constituyen dos de las cuatro principales unidades morfoestructurales de Chile junto a la planicie litoral y la Cordillera de la Costa, que forman así cuatro fajas longitudinales paralelas entre sí a lo largo de casi todo el país, generadas tras la intensa actividad tectónica del Terciario (Börgel, 1993). 
En la depresión intermedia se encuentra la cuenca tectónica de Santiago, presentando alturas entre 450 y 650 m.s.n.m. La depresión es una zona de sedimentación de materiales no consolidados de origen fluvio-glacio-volcánico, provenientes de las rocas que conforman la Cordillera de los Andes. La surcan dos ríos importantes: el Maipo y el Mapocho, afluente del primero que desemboca en el Océano Pacífico, tal y como se aprecia en la figura 2.

\subsection{Clima}

En el diagrama ombrotérmico derivado de los datos proporcionados por la estación de Cerro Calán- situada 5 km al noroeste- para el periodo 1982-2013 (fig. 5), se observa que las precipitaciones tienen un comportamiento irregular a lo largo del año, pues casi el 75\% de las lluvias se concentran entre los meses de mayo y agosto, principalmente en junio $(99,55 \mathrm{~mm}$ ) y julio $(91,14 \mathrm{~mm}$ ) (DGA, 2014). De acuerdo con el diagrama, existe además un período seco de 7 meses, durante los cuales apenas se recogen 70 $\mathrm{mm}$ de lluvia de los $323 \mathrm{~mm}$ anuales que se registran de media (Pérez Jara, 2011), siendo diciembre, enero y febrero los meses más críticos (8 mm en total) (DGA, 2014).

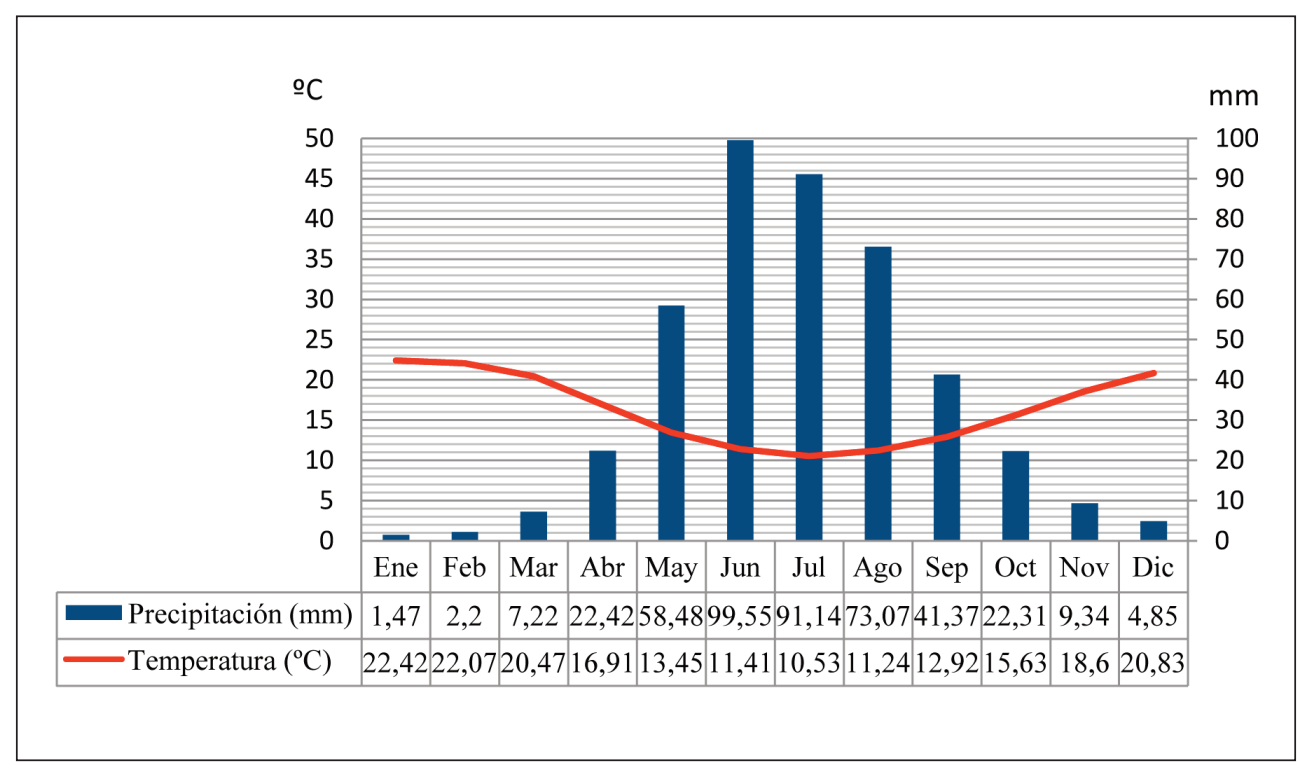

Figura 5. Diagrama ombrotérmico de la estación Cerro Calán.

Fuente: Elaboración propia a partir del banco de datos de la Dirección General de Aguas. 
En cuanto al comportamiento de las precipitaciones máximas en 24 horas, el análisis estadístico muestra que existe una gran heterogeneidad en las mediciones. La media de la serie de datos es de $59,75 \mathrm{~mm}$, pero las precipitaciones máximas se mueven entre los $25 \mathrm{~mm}$ y los $145 \mathrm{~mm}$ en 24 horas, lo cual dificulta la identificación de tendencias (DGA, 2014). Con respecto a las precipitaciones máximas en 24 horas esperadas para diferentes periodos de retorno, los resultados obtenidos se muestran en la tabla 1.

Tabla 1. Precipitaciones máximas en 24 horas esperadas para distintos periodos de retorno (T)

\begin{tabular}{|c|l|c|}
\hline$T$ (años) & $F(X)$ & Precip. máxima en $24 \mathrm{~h}(\mathrm{~mm})$ \\
\hline 2 & 0,5 & 55,41 \\
5 & 0,8 & 84,1 \\
10 & 0,9 & 103,09 \\
25 & 0,96 & 127,09 \\
50 & 0,98 & 144,89 \\
100 & 0,99 & 162,57 \\
200 & 0,995 & 180,17 \\
500 & 0,998 & 203,4 \\
\hline
\end{tabular}

Fuente: Elaboración propia a partir de los datos proporcionados por la Dirección General de Aguas.

De la curva de temperaturas se infiere que se trata de un clima templado, con una temperatura media de $13,9^{\circ} \mathrm{C}$ (BCN, 2014), donde se diferencian notablemente las distintas estaciones. Julio es el mes más frío, aunque el invierno no se alarga más de tres meses en total.

Esta interpretación del diagrama se corresponde notablemente con la descripción del clima para Chile Central de varias clasificaciones climáticas. De acuerdo con la clasificación climática de Köppen, se trata de una región climática Csb, que corresponde a climas templados cálidos con lluvias suficientes, sin excluir la posibilidad de estaciones secas prolongadas, como ocurre aquí en los meses estivales.

\subsection{Demografía y usos del suelo en La Reina y Las Condes}

La Quebrada de Ramón penetra en la ciudad de Santiago por el municipio o comuna de Las Condes (fig. 6), recorriendo un pequeño sector meridional de ella hasta entrar dentro de los límites del municipio de La Reina. Las Condes se sitúa en el Sector Oriente de Santiago de Chile, contaba con 246.474 habitantes en 2002 (Municipa- 
lidad de Las Condes, 2014), y la quebrada no atraviesa ninguna de sus zonas urbanas, de forma que la exposición de esta comuna es mucho menor. Aún así, cerca del río existen otro tipo de ocupaciones del suelo altamente expuestas a amenazas por inundación, tal y como se analizará más adelante.

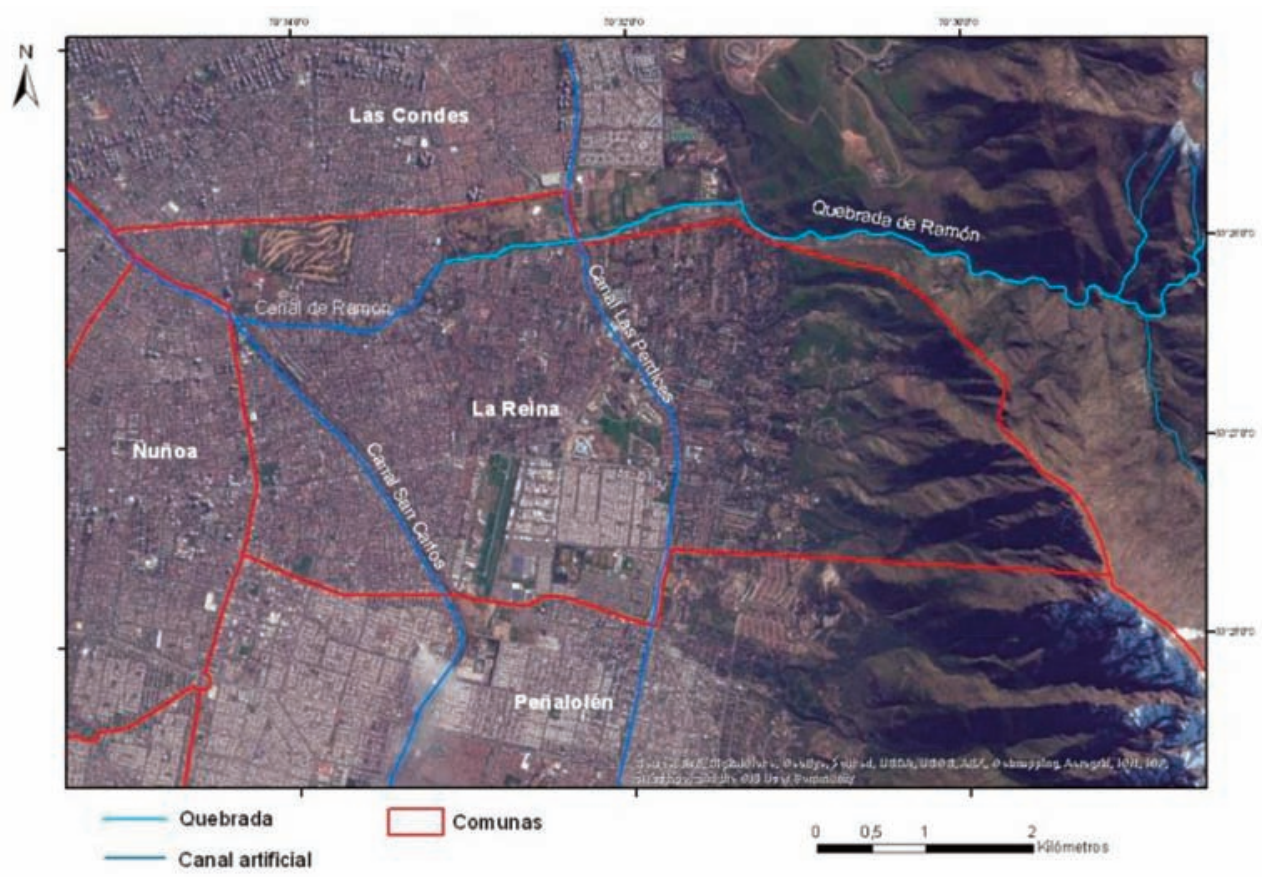

Figura 6. Red hidrográfica y división de las comunas o municipios. Fuente: Elaboración propia a partir de la información del CIT de la UAI (2011).

El municipio que realmente es atravesado por la Quebrada de Ramón es La Reina, y por lo tanto, son sus habitantes los que han sufrido los problemas derivados de las crecidas. La Reina también está situada en el Sector Oriente del Gran Santiago, en terrenos precordilleranos con pendiente creciente, desde 600 m.s.n.m hasta 2000 m.s.n.m y limita al norte y al este con Las Condes. De acuerdo con el Censo 2002, el municipio contaba en ese momento con 96.762 habitantes repartidos en un total de 25.768 viviendas. El poblamiento de La Reina se ha realizado de poniente a oriente hacia la zona alta, y su superficie, de $23,4 \mathrm{~km}^{2}$, está surcada por los canales San Carlos, Ramón y Las Perdices, cumpliendo funciones de riego, recogida y transporte de aguas lluvias. 


\section{Marco normativo sobre planificación de zonas inundables}

El origen de la problemática sobre inundaciones en distintas áreas urbanas de Chile, entre ellas en la comuna de La Reina, reside en la fuerte expansión urbana ocurrida principalmente en las décadas de 1980 y 1990, sin llegar a desarrollarse correctamente inversiones necesarias en materia de evacuación y drenaje de aguas lluvias (Dirección de Obras Hidráulicas, 2013). El aumento de la superficie urbanizada fue una consecuencia directa de la Política Nacional de Desarrollo Urbano de 1979, aprobada durante la dictadura del General Augusto Pinochet. Esta política neoliberal consideraba el suelo urbano como un recurso no escaso, defendiendo la aplicación de sistemas flexibles de planificación para permitir el crecimiento de las áreas urbanas de acuerdo con la tendencia del mercado (Ministerio de Vivienda y Urbanismo, 1979), lo que trajo consigo un incremento de las áreas impermeables y, por consiguiente, de la escorrentía superficial, la cual puede traducirse en caudales que provocan desbordamientos e inundaciones.

El Plan Regulador Metropolitano de Santiago (PRMS) define en el título 8 el Área Restringida o Excluida al Desarrollo Urbano. Dentro de las sub-áreas que la comprenden, son las Áreas de Alto Riesgo para los Asentamientos Humanos las de mayor interés para este estudio. Dentro de este espacio, el Plan realiza una nueva categorización de áreas, aunque este análisis se centrará en las Áreas de Alto Riesgo Natural por Inundación. En la sub-categoría de "Cauces naturales", en las áreas de "Amagadas de Inundación", se ordena que "los instrumentos de Planificación Local deben reconocer estas áreas" (Ministerio de Vivienda y Urbanismo, 2010, pág. 112). Asimismo, para la sub-área de "Quebradas", el PRMS impone una franja de 100 metros de restricción a cada lado del cauce, donde "sólo se permitirá el equipamiento de áreas verdes, recreacional-deportivo y de esparcimiento-turismo, con las instalaciones minimas complementarias a actividades al aire libre que no impliquen concentración masiva o permanencia prolongada de personas" (Ministerio de Vivienda y Urbanismo, 2010, pág. 112). Esta norma se cumple parcialmente, pues aunque existen zonas con equipamientos recreacionales, deportivos y de esparcimiento, hay ocupación residencial y faltan más áreas verdes, que son más compatibles con las características con la capacidad de acogida del lugar.

El PRMS también recuerda que los Planes Reguladores Comunales deben reconocer y normar las áreas urbanizadas afectadas por riesgo de inundación con el fin de minimizar dicho problema. Para ello, deberían establecerse exigencias urbanísticas y condiciones de edificación, e incluso propone que debería prohibirse el uso residencial, algo que no ha ocurrido en las zonas residenciales afectadas de La Reina.

Con respecto a la sub-categoría de "Cauces artificiales", que para el caso del área de estudio hace referencia al trayecto entre el Canal las Perdices y la desembocadura en el Canal San Carlos, los proyectos tienen que consultar franjas de protección según lo establecido por el organismo competente en cada caso. Tal y como se verá con mayor detalle en un análisis posterior, estas franjas no existen. 
Finalmente, la normativa que debe analizarse imprescindiblemente es el Plan Regulador Comunal de La Reina (PRCLR). En el Capítulo V del Plan, dentro del Artículo 23 dedicado a la zonificación, se menciona que el territorio urbano de la comuna de La Reina está configurado por una serie de zonas. Dentro de la Zona R correspondiente a "Áreas Restringidas o Excluidas del Desarrollo Urbano" existe la Subzona R1 llamada "Áreas Amagadas por Inundación", "constituidas por los terrenos consolidados, con edificaciones adyacentes a puntos de desbordes de cauces permanentes, con peligro de inundación como es la Quebrada de Ramón” (Municipalidad La Reina, 2010, pág. 60), por lo cual, aporta entre otras cosas unas normas específicas de edificación y el Plano de Zonificación, que especifica usos del suelo y normas urbanísticas para estas zonas.

La Subzona R2 del PRCLR, correspondiente a la zona del río denominada "quebrada" desde el límite urbano hasta el Canal Las Perdices, recoge la misma normativa descrita en el PRMS. Mientras tanto, la Subzona R3 "Cauces artificiales" hace referencia a los canales Las Perdices, San Carlos y Ramón (en su tramo bajo, convertido en canal artificial). De acuerdo con la normativa, "los proyectos de canalización de aguas a tajo abierto o entubados, deberán consultar fajas de protección a ambos costados del borde del cauce", advirtiendo además que "la faja de protección no será construible y tendrá un minimo de 3 metros desde el borde del cauce hasta el eje medianero" (Municipalidad La Reina, 2010, pág. 64). A su vez, se especifica que los predios colindantes a los canales "deberán respetar una faja de minimo 3 metros de ancho desde el eje medianero hacia el interior, sin construir" (Municipalidad La Reina, 2010, pág. 64). Una vez más, pese a la existencia de una normativa que establece fajas de protección adyacentes a un canal, aún existen tramos donde el río discurre encajonado entre casas.

\section{Diagnóstico}

\subsection{Comportamiento de los caudales}

Un análisis de los caudales medios mensuales para el periodo 1991-2013 (DGA, 2014) permite observar el comportamiento regular del caudal de la Quebrada de Ramón a su paso por la estación de aforo Recinto Emos. Debe tenerse en cuenta que, debido a que el área de estudio se encuentra en el hemisferio sur, el año hidrológico comienza en abril y termina en marzo del año siguiente.

Existe una correlación entre los meses con mayores caudales medios y la distribución anual de las precipitaciones. Puede observarse cómo el caudal medio comienza a crecer a partir de mayo coincidiendo con el inicio de las lluvias invernales, y sigue creciendo hasta alcanzar su máximo en agosto. Se aprecia cómo se dan ciertas divergencias en la tendencia entre el caudal y las precipitaciones fruto del carácter sólido de las mismas en los meses más fríos, como julio, mientras que en agosto aumenta el 
caudal como consecuencia de algo de fusión nival y de los procesos de escorrentía subsuperficial a pesar de que el volumen de precipitaciones disminuye. A partir de septiembre, se produce un descenso de caudal ligado a la disminución de las precipitaciones. Sin embargo, vuelve a crecer ligeramente con el inicio del periodo estival seco, aunque no se alcanzan los niveles de caudales medios invernales, lo que refleja que el régimen de la quebrada es pluvionival. El caudal disminuye progresivamente desde diciembre hasta abril (mes con caudal medio mínimo), consecuencia directa del periodo seco que puede llegar a alargarse desde octubre hasta abril.

A pesar de todo, se tratan de caudales medios muy bajos, propios de arroyos o torrentes, que contrastan con los 6,1 m³ $/ \mathrm{s}$ (CentroGeo, 2014) de media del río Mapocho y los $92,3 \mathrm{~m}^{3} / \mathrm{s}$ (Biblioteca del Congreso Nacional de Chile, 2014) del río Maipo, el más importante de la región.

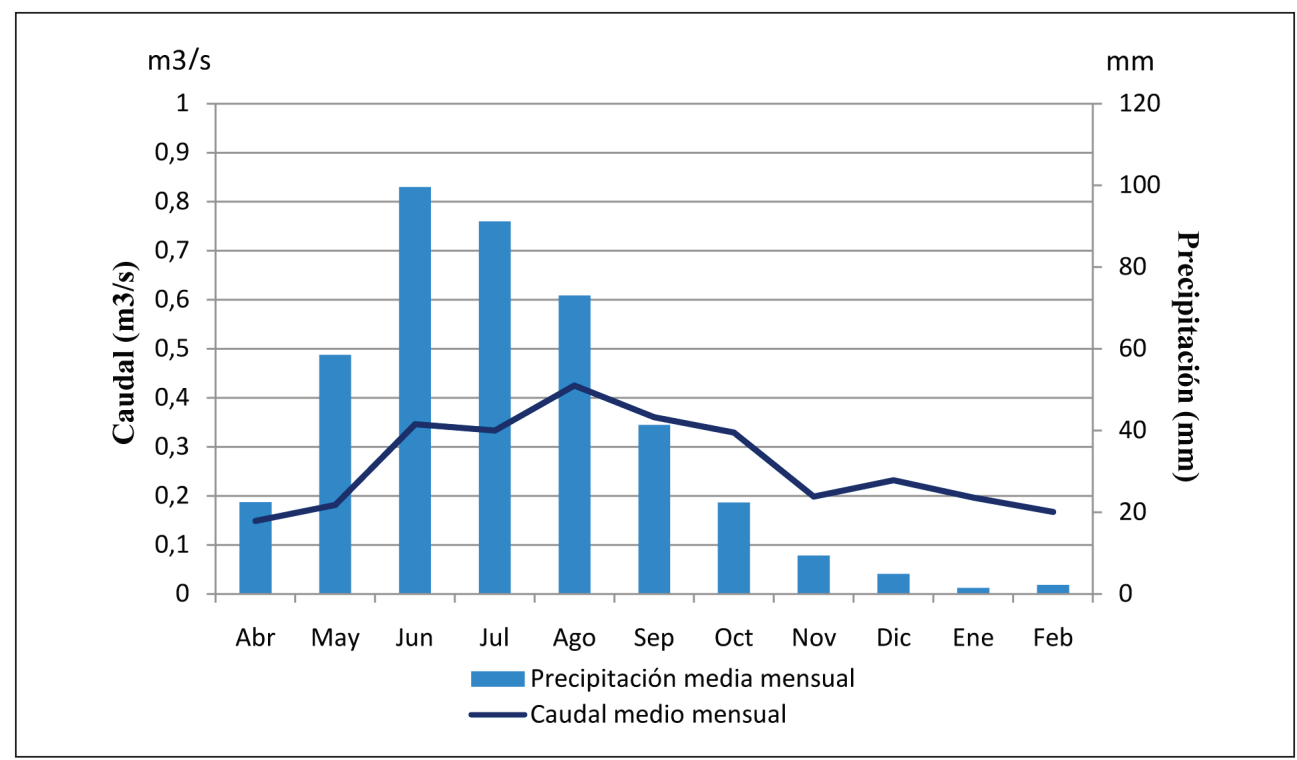

Figura 7. Caudal medio mensual de la Quebrada de Ramón en Recinto Emos y precipitación media mensual medida en Cerro Calán.

Fuente: Elaboración propia a partir de los datos proporcionados por la Dirección General de Aguas.

Con respecto a los eventos extremos, y a partir del ajuste de Gumbel, se han realizado cálculos para estimar el caudal máximo instantáneo para distintos periodos de retorno, los cuales se muestran en la tabla 2. Se trata, por otro lado, de unos datos extremadamente heterogéneos, lo que representa el carácter generalmente intenso de las precipitaciones y la gran variación del caudal de los torrentes en relación directa con estas lluvias. 
Tabla 2. Caudal máximo instantáneo (Qci) esperado para distintos periodos de retorno (T)

\begin{tabular}{|c|l|c|}
\hline T(años) & $F(X)$ & $Q c i\left(\mathrm{~m}^{3} / \mathrm{s}\right)$ \\
\hline 2 & 0,5 & 3,94 \\
5 & 0,8 & 11,56 \\
10 & 0,9 & 16,61 \\
25 & 0,96 & 22,99 \\
50 & 0,98 & 27,73 \\
100 & 0,99 & 32,42 \\
200 & 0,995 & 37,1 \\
500 & 0,998 & 43,28 \\
\hline
\end{tabular}

Fuente: Elaboración propia a partir de los datos proporcionados por la Dirección General de Aguas.

\subsection{Diagnóstico sobre la normativa vigente}

Se diferenciarán dos sectores basándose en la zonificación de restricción elaborada por el PRCLR, que considera dos áreas de alto riesgo natural por inundación: las quebradas o Subzona R2 (el cauce es mayoritariamente natural) y las áreas amagadas por inundación o Subzona R1 (se relacionan con el tramo canalizado del río).

El tramo del río que se denomina "quebrada" (Subzona R2) es, por lo tanto, el que conserva su cauce natural sin demasiadas intervenciones humanas, aunque existen algunas defensas de gaviones y un puente (MOP, 1996), y es el sector con menor presión urbana, por lo que las crecidas suponen aquí una menor amenaza. El PRMS define el ancho de la franja de restricción de usos de la Quebrada de Ramón, situándolo en 100 metros a cada orilla. Esta misma franja está incluida en el PRCLR como Subzona R2, y para su definición fue utilizada la extensión de la lámina de inundación para un período de retorno de 100 años, siendo esta la norma para la construcción de viviendas.

Con respecto a los usos del suelo dentro de la franja de 100 metros, debe matizarse que la mayor parte de esta área corresponde al municipio vecino de Las Condes. Todo el sector que queda dentro de la franja está considerado en la categoría "Parque comunal e intercomunal". Sorprende ver que el PRC de Las Condes solo concede 25 metros de ancho en cada orilla a la franja de restricción de la Quebrada de Ramón, lo que provoca que el Centro de Estudios Nucleares quede aparentemente fuera de cualquier amenaza de inundación. Así pues, cabe destacar que existe una clara descoordinación entre la planificación metropolitana y la municipal, ya que la franja de restricción de 100 metros definida por el PRMS sí que incluye estas instalaciones, y además, la superficie de la lámina de inundación para un periodo de retorno de 100 años muestra que este lugar quedaría afectado. 
Entre los otros usos del suelo de la comuna de Las Condes dentro de la franja, se encuentran una pista de karts, parte de un parking, varias edificaciones aisladas, descampados y prados con vegetación arbórea, campos de fútbol, parte de un terreno particular, descampados, una serie de caminos que transcurren paralelos a la quebrada, una carretera y una serie de edificaciones acompañadas de un aparcamiento.

Las áreas de la comuna de La Reina que quedan dentro de la franja (Subzona R2) son de uso preferentemente residencial, y pese a que no quedan afectadas por la lámina de inundación de 100 años, su ubicación las hace estar más expuestas a posibles amenazas de desbordamiento. Así, puede concluirse que este sector de la comuna posee una buena planificación sobre zonas restringidas, pero su efectividad se ve disminuida por ser posterior a la consolidación de las áreas urbanas, generalmente residenciales, que ya se encontraban ahí. Por esta razón, la mayoría de los usos del suelo dentro de la franja son incompatibles con la planificación vigente.

La Subzona R1 se refiere a las áreas afectadas por una potencial inundación del tramo encauzado y canalizado del río. La zonificación cartografiada del PRCLR muestra que los usos del suelo que quedan dentro de la zona de restricción son preferentemente residenciales. En este sector el canal circula entre casas, de manera que se encuentra totalmente constreñido y supone una seria amenaza para los vecinos de los predios contiguos al canal. De hecho, por esta misma razón, no existe la faja de protección de 3 metros no construible desde el borde del cauce hasta el eje medianero, y adicionalmente, los terrenos colindantes tampoco respetan una franja de 3 metros sin construir desde el eje medianero hacia el interior.

De acuerdo con la literatura y las noticias publicadas al respecto, el punto más conflictivo en cuanto a desbordes e inundabilidad ha sido hasta la fecha el nodo vial del sector Príncipe de Gales, tramo en el cual el canal queda entubado. Durante el año 2010, tras las graves inundaciones de agosto de 2005, se realizaron obras de construcción del nuevo conducto bajo el nudo vial de estas calles. La nueva capacidad hidráulica del canal en este sector es de $20 \mathrm{~m}^{3}$ /s (Municipalidad La Reina, 2011), sin embargo, el análisis de caudales máximos instantáneos esperados para distintos periodos de retorno muestra que se esperan caudales superiores a $20 \mathrm{~m} 3 / \mathrm{s}$ cada menos de 25 años (ver tabla 2), lo que significa que esta obra por sí sola no bastaría para disminuir el riesgo de desbordamiento.

Pese a que la zonificación de esta área de restricción es muy amplia, el PRCLR parte de una realidad en la cual todo el borde del canal y las áreas con riesgo de inundación están totalmente urbanizadas (fig. 8), con lo cual, los efectos de reducción del riesgo del PRCLR son prácticamente inexistentes. Por otro lado, pese a establecer unas normas de edificación y construcción de subterráneos, no se da mayor detalle sobre normas de evacuación y drenaje de las aguas. 


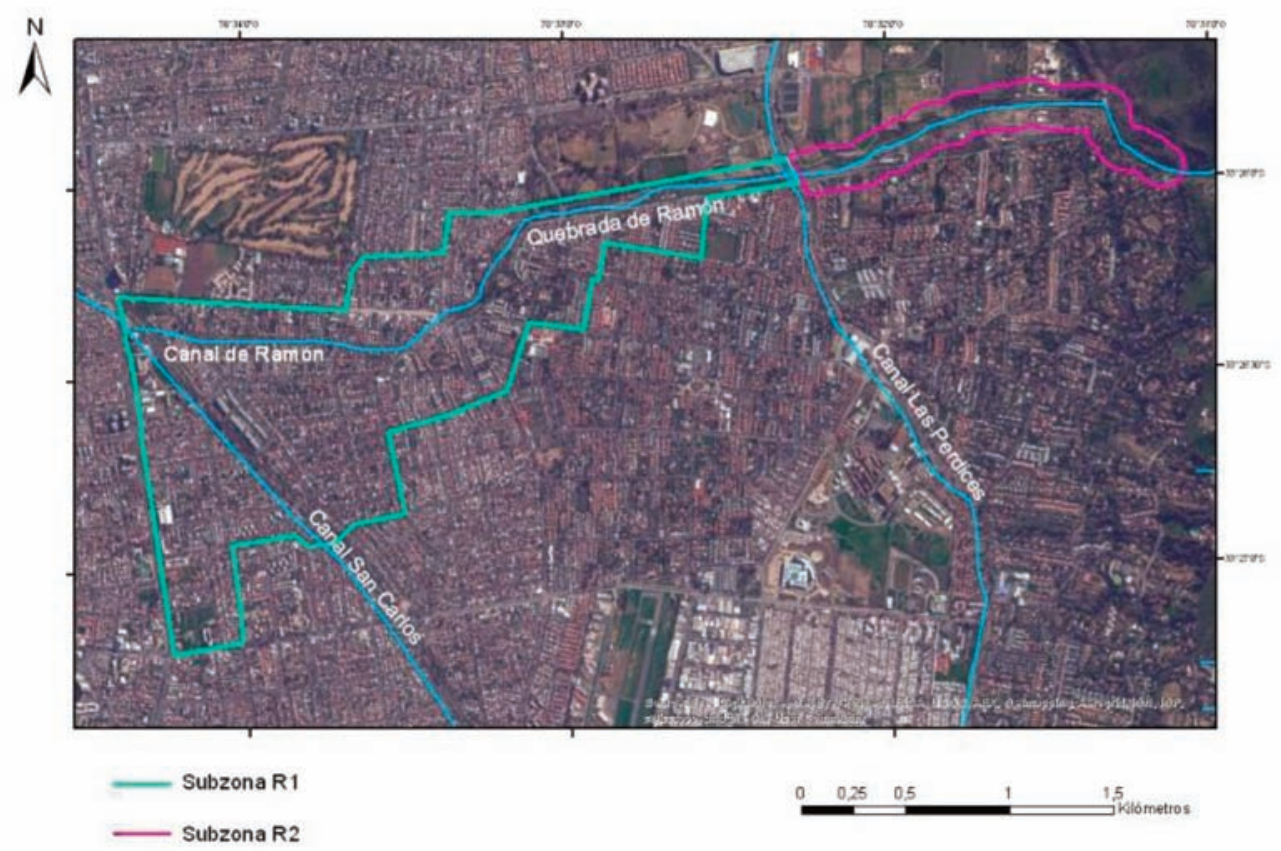

Figura 8. Subzonas R1 y R2 del PRCLR.

Fuente: Elaboración propia a partir de Municipalidad de La Reina (2001).

\section{Propuestas}

La base sobre la cual se elaborará una nueva propuesta de planificación de las zonas inundables será la recuperación del Territorio Fluvial. Este término, cuya utilización se estableció en la Estrategia Nacional de Restauración de Ríos desarrollada en España como parte de las medidas contempladas para la aplicación de la Directiva Marco de Aguas, hace referencia al espacio comprendido por el cauce, el corredor ribereño y la llanura de inundación (total o parcial) y es el que pretende ser reivindicado como territorio necesario para "conservar o recuperar la dinámica hidrogeomorfológica, obtener un corredor ribereño continuo que garantizaría la diversidad ecológica (...), cumplir con el buen estado ecológico, laminar de forma natural las avenidas, resolver problemas de ordenación de áreas inundables, así como mejorar y consolidar el paisaje fluvial" (Ollero et al., 2010).

El primer paso para la elaboración de la nueva propuesta de planificación ha sido la delimitación del Territorio Fluvial correspondiente a la Quebrada y el Canal de Ramón, desde el límite urbano hasta la desembocadura en el Canal San Carlos. Los criterios uti- 
lizados para dicha delimitación han variado a lo largo del tramo, pero la regla común ha consistido en tratar de incorporar en todo momento el cauce, el corredor ribereño y parte de la llanura de inundación en base a criterios geomorfológico-topográficos. Lamentablemente, en este paso no se ha podido contar con fotos aéreas antiguas.

La identificación de estos tres territorios ha sido más sencilla en el tramo superior denominado "quebrada", por ser este el sector menos ocupado. Aquí, la delimitación ha tenido como base el ancho de la franja de restricción de 100 metros definida por el PRMS (fig. 9). En el tramo que discurre junto al Parque Padre Hurtado y en el sector plenamente urbano (fig. 10), la delimitación se ha basado en gran medida en la extensión del Territorio Fluvial en el tramo superior, ya que la total ocupación del territorio por parte de la ciudad y la topografía llana dificultan la delimitación en base a criterios geomorfológico-topográficos. En el caso del Parque Padre Hurtado, la delimitación se ha efectuado a partir de la extensión de la Subzona R1 del PRCLR, referente a las áreas amagadas por inundación. En el sector entre las calles Florencio Barrios y Príncipe de Gales, el territorio también ha sido definido mediante la inclusión del área verde situada en la margen derecha del canal (fig. 11). Por otro lado, en el tramo entre Príncipe de Gales y la desembocadura, se le ha concedido más anchura en la margen izquierda en base a la mayor extensión que posee aquí la subzona de amagadas por inundación, lo que puede significar que la llanura de inundación sea más extensa (fig. 12).

La superficie que ocupa este territorio sería aplicable en un escenario ideal, donde abundasen los recursos económicos, la voluntad de las autoridades y la voluntad de todos los vecinos que deberían abandonar sus casas y estar dispuestos a trasladarse a otro lugar más seguro. No obstante, las propuestas de actuación se limitan a una porción del Territorio Fluvial, en especial en las áreas totalmente urbanizadas del municipio de La Reina:

\section{a. Parque inundable}

La principal alternativa para la implementación del Territorio Fluvial es la conversión de una parte de este en un parque inundable, es decir, un espacio sobre el cuál puedan laminarse las avenidas y evitar así que lleguen grandes caudales al sector más urbano, donde la quebrada se encuentra encauzada y muy constreñida. Se propone que se extienda a lo largo de 3,5 km desde el límite urbano hasta la avenida Príncipe de Gales, estaría dotado de una infraestructura básica que no requiera grandes gastos en caso de restauración tras una inundación, y sus áreas inundables se cerrarían al público en situaciones de alerta por crecida. Así pues, estas serían las propuestas particulares para lograr la implementación del parque inundable, de este a oeste y por sectores. 


\section{Tramo limite urbano-Padre Hurtado (figura 9)}

- En el curso alto del río, se propone la construcción de una mota en la orilla cercana al Centro de Estudios Nucleares de La Reina para derivar la crecida hacia la llanura sur de la quebrada y facilitar su inundación (junto con un rebaje de la cota de esta llanura), también con el fin de proteger a estas instalaciones de una probable crecida de gran magnitud.

- Se proponen numerosos cambios de uso de suelo que afectarían a varias ocupaciones actuales como un parking, una pista de karts y otras edificaciones de baja densidad que por norma no deberían existir por estar situadas en un área restringida. Todos estos usos pasarían a formar parte del parque inundable, debiendo plantearse alternativas para la relocalización de las actividades.

- Como medida adicional, se sugiere el cambio de uso del espacio ocupado por el grupo de viviendas situado en las cercanías de la confluencia de la Quebrada de Ramón y el Canal Las Perdices, ya que se encuentra dentro de los límites de restricción de la Subzona R2 del PRCLR, por otro compatible con la inundabilidad. Estas viviendas serían relocalizadas en sectores cercanos y libres de amenazas por inundación, aunque también debería considerarse el nivel socio-económico de las familias afectadas.

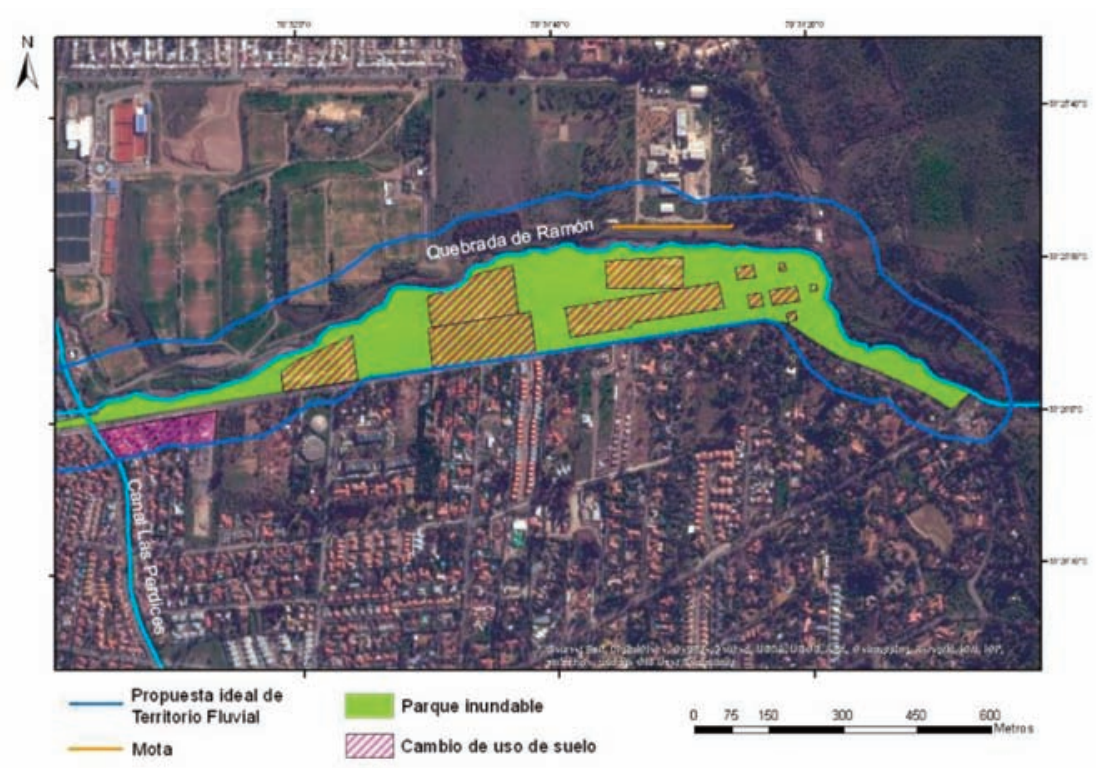

Figura 9. Propuesta de planificación del tramo de la Quebrada entre el límite urbano y la calle Padre Hurtado.

Fuente: Elaboración propia. 


\section{Tramo Padre Hurtado-Florencio Barrios (figura 10)}

En este sector, la Quebrada de Ramón discurre encauzada y a través de piscinas de decantación, y de acuerdo con la zonificación de las áreas amagadas por inundación del PRC de La Reina, se trata de una zona con poco riesgo. Por esta razón, las principales actuaciones propuestas son las siguientes:

- Continuación del parque inundable, que tendría una anchura reducida por el escaso espacio disponible entre la carretera y el cauce.

- Para justificar el mantenimiento de las viviendas situadas al sur de la quebrada, se propone favorecer la inundación de la margen derecha (Parque Padre Hurtado), para disminuir así el riesgo de inundación en la zona inundable de la margen izquierda.

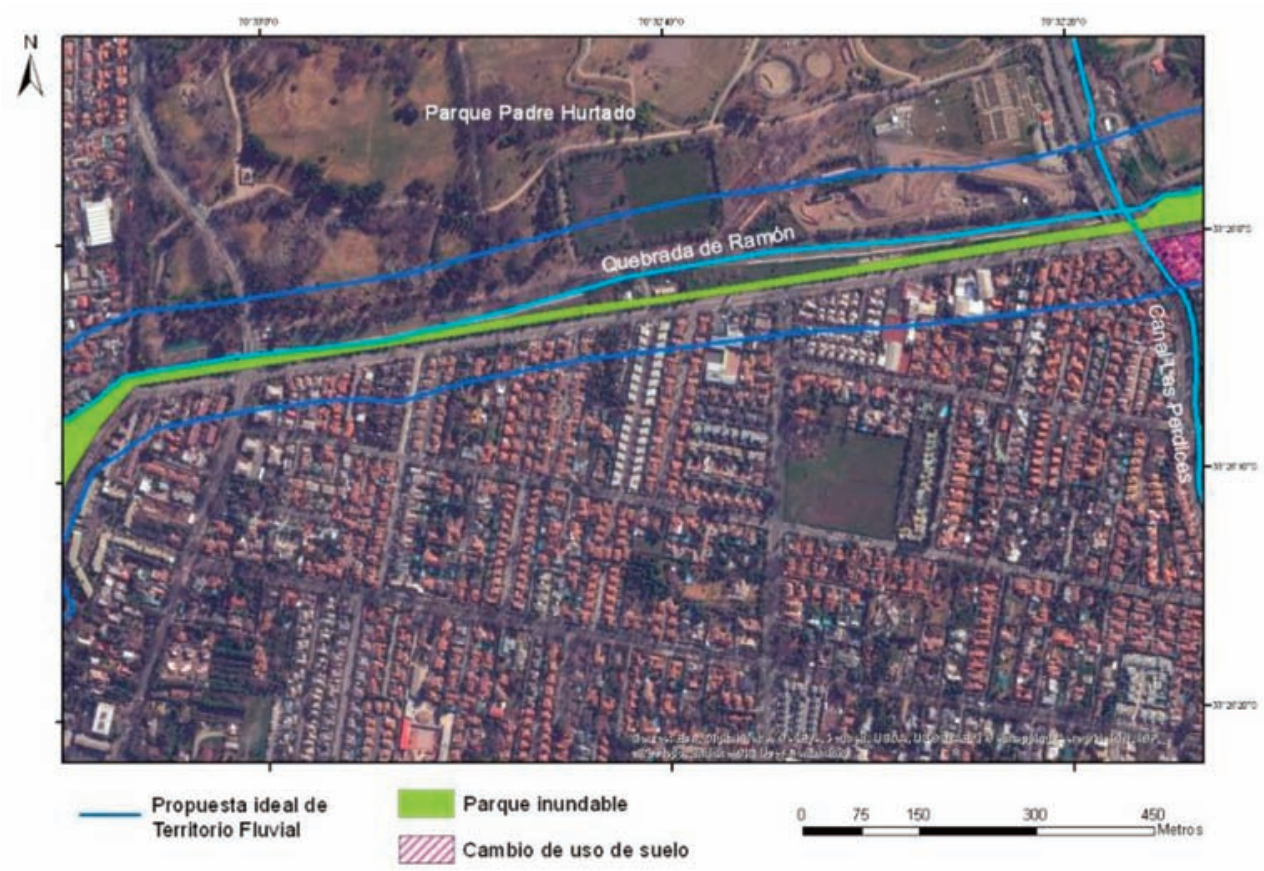

Figura 10. Propuesta de planificación del tramo de la Quebrada entre las calles Padre Hurtado y Florencio Barrios.

Fuente: Elaboración propia. 


\section{Tramo Florencio Barrios-Príncipe de Gales (figura 11)}

- La propuesta más importante está relacionada con la continuación del parque inundable, que en este caso abarcaría casi la totalidad de un área verde actual. Para permitir la inundación del nuevo parque, se generaría un rebaje de la cota de la llanura ocupada por el área verde actual, así como una serie de rupturas en la pared oriental del canal, de tal forma que se facilite la inundación del parque y se evite la llegada de caudales altos al nodo vial de Príncipe de Gales, el que históricamente más problemas y daños ha registrado.

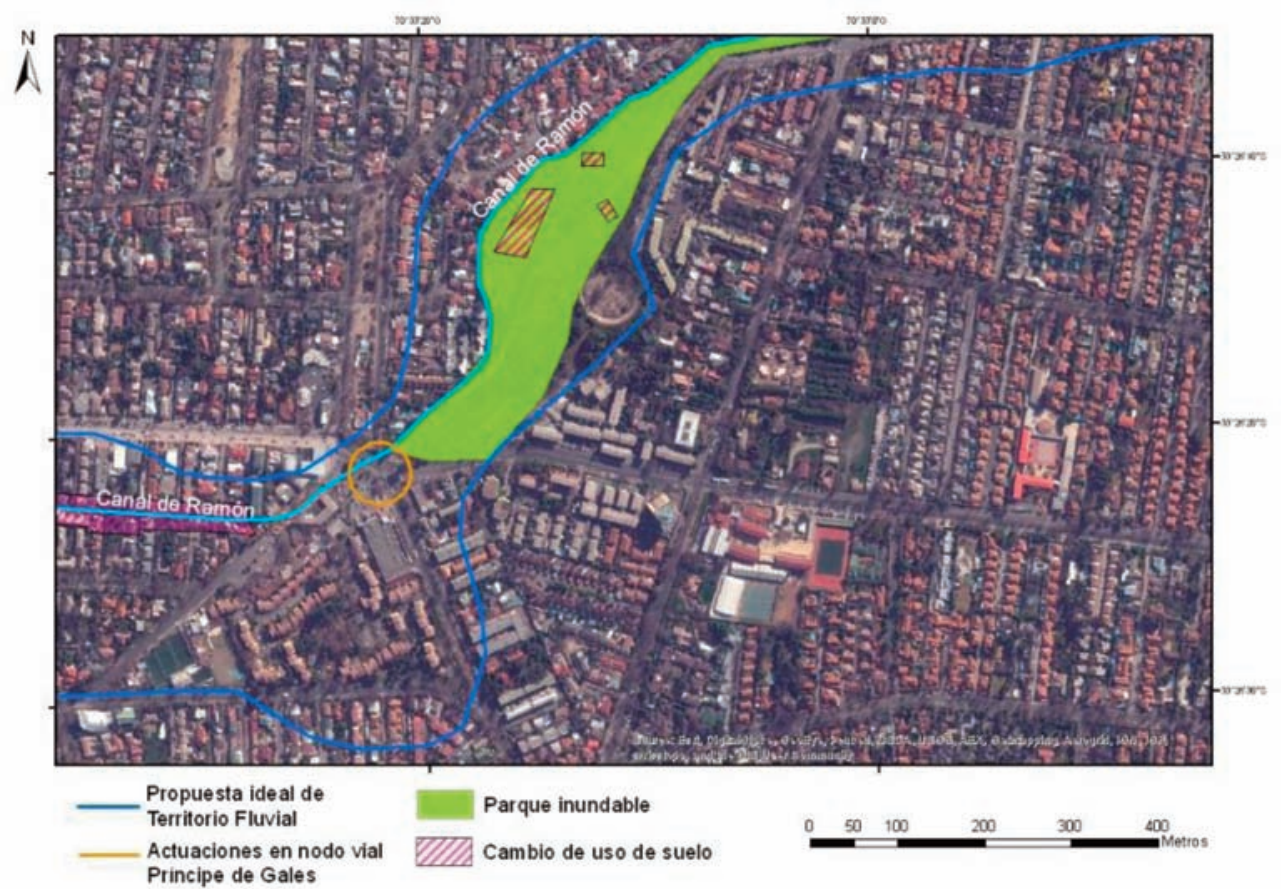

Figura 11. Propuesta de planificación del tramo del Canal de Ramón entre Florencio Barrios y Príncipe de Gales.

Fuente: Elaboración propia.

\section{b. Ensanchamiento del canal}

La propuesta de ensanchamiento del canal se llevaría a cabo en el sector correspondiente al último tramo del Canal de Ramón, desde el nodo vial de Príncipe de Gales hasta su desembocadura en el Canal San Carlos, donde discurre totalmente constreñido entre viviendas unifamiliares. Para ello, se proponen las siguientes actuaciones: 
- El conducto entubado bajo este nodo vial (fig. 11) debería volver a ser reformado para aumentar su capacidad hasta los $45 \mathrm{~m}^{3} / \mathrm{s}$, que es el caudal esperado para un periodo de retorno de 500 años, y reducir con mayor seguridad el riesgo de inundación de esta zona.

- Realizar un cambio de uso en la primera línea de viviendas a cada orilla del canal (o al menos en una de las dos líneas) con el objetivo de aumentar la capacidad del canal hasta los $45 \mathrm{~m}^{3} / \mathrm{s}$ (fig. 12), asegurándose la reubicación de las familias en sectores próximos y libres de amenazas naturales y teniendo siempre en cuenta el nivel socio-económico de estos hogares. Esta propuesta se plantea en base al PRMS, que dicta que para el caso de las áreas con alto riesgo para los asentamientos humanos, la intensidad de ocupación del suelo debería restringirse.

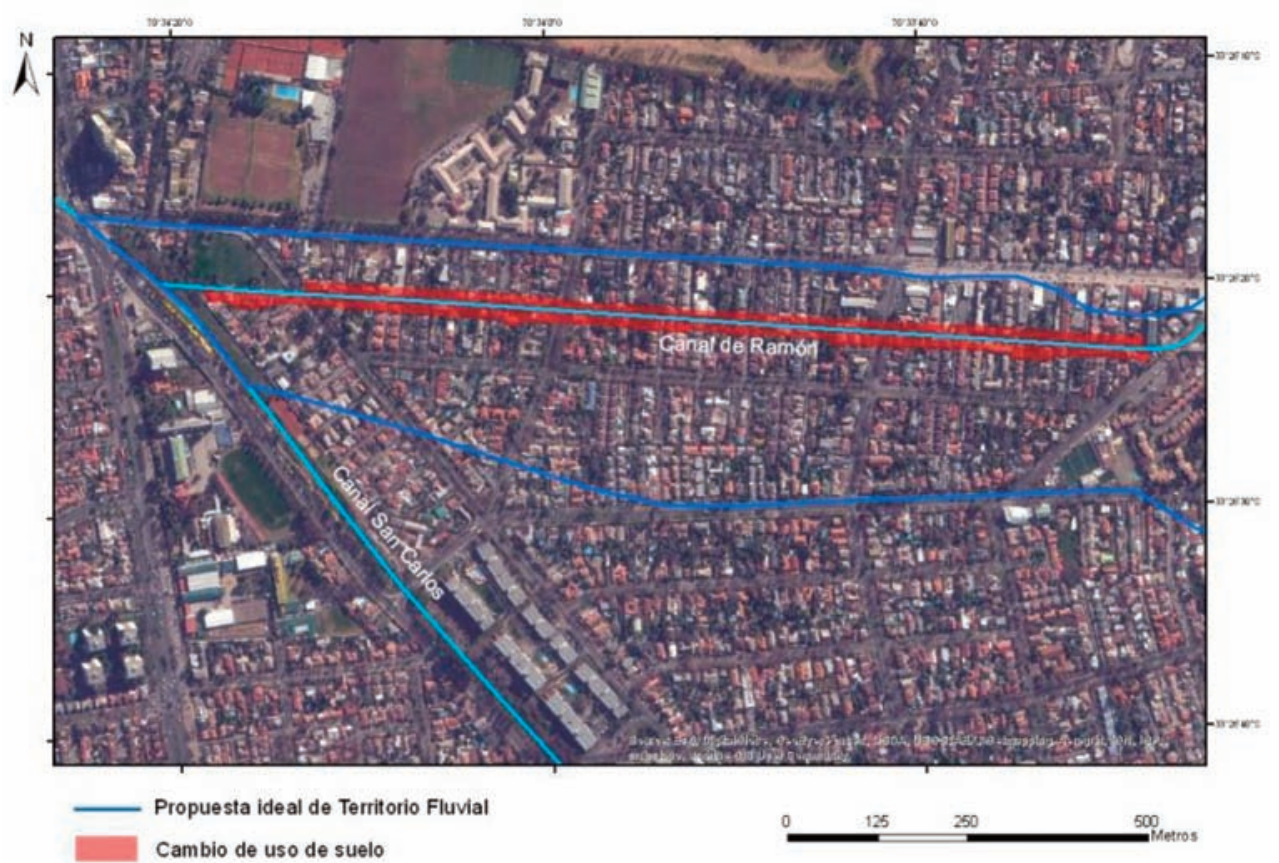

Figura 12. Propuesta de planificación del tramo del Canal de Ramón entre Príncipe de Gales y la desembocadura.

Fuente: Elaboración propia. 


\section{c. Instrumentos normativos}

En lo referente a las actuaciones en materia de instrumentos normativos, se plantean las siguientes propuestas:

- Aprobación definitiva del actual proyecto de Ley del Sistema Nacional de Emergencia y Protección Civil, que entre otras medidas, plantea crear un Fondo Nacional de Protección Civil. Desde el punto de vista de la gestión del riesgo de desastres, este fondo no debería estar enfocado solamente a la atención de emergencias, sino también a la reducción del riesgo. Además, tiene que ser acumulativo y debe plantearse como fuente de financiación de indemnizaciones tras la expropiación de terrenos y viviendas en zonas de alto riesgo natural.

- Creación de un Fondo Municipal de Gestión del Riesgo de Desastres, que también sea acumulativo y que financie actuaciones de coste menor a nivel municipal. En materia de inundaciones, se contempla que el Fondo Municipal debe financiar la ejecución de planes y simulacros de evacuación, las intervenciones de ayuda y rescate post-desastre, la creación del parque inundable en colaboración con la municipalidad de Las Condes y el aumento de la red de monitoreo de caudales y datos meteorológicos de la cuenca de la Quebrada de Ramón, también en colaboración con la municipalidad vecina.

La eficacia de estas propuestas está basada en la mitigación del riesgo de inundación en zonas urbanas a través de actuaciones que garanticen una laminación natural de las crecidas y permitan un flujo más libre de las aguas sin afectar a núcleos habitados; es decir, está basada en una actuación de ordenación territorial donde queda incorporada la gestión del riesgo de desastres, de forma que también pueda servir de ejemplo para otras ciudades.

La actual construcción del Parque Inundable La Aguada, en la zona central del Gran Santiago, puede suponer un importante ejemplo de eficacia, pues se trata del primer "hidroparque" de la ciudad. De esta forma, se busca poner fin a la problemática de las inundaciones entregando a su vez nuevos espacios de recreación para la ciudad (Concha, 2014). Otro antecedente es la propuesta de creación de una red seca de inundación del arquitecto urbanista Jonás Figueroa. Esta red seca restituiría las quebradas naturales que transcurren por la ciudad y se expresaría como un sistema de parques lineales, arborizados en los bordes y con una hondonada central para que discurra el agua, que además supondría una oportunidad para reurbanizar extensas áreas carentes de centralidad y atributos (Figueroa, 2000).

En ciudades grandes como Santiago de Chile, el riesgo se incrementa por ser un lugar privilegiado para la ocurrencia de desastres. No obstante, las urbes son también el principal escenario para el desarrollo de oportunidades, entre las que se encuentran "la conformación de asentamientos sustentables y (...) la construcción de una "cultura de prevención"” (Sánchez, 2010, pág. 7). 
En cuanto a la gestión del riesgo en Chile, a partir de los años 90 comenzó a incorporarse una visión más integral del riesgo, una visión que no solo se enfoca en las etapas de respuesta y recuperación, sino también en la prevención de eventos destructivos (Stötter y Zischg, 2008). Sin embargo, pese a la aprobación del Plan Nacional de Protección Civil (PNPC) en 2002 (planificado a partir de una visión integral del manejo del riesgo) y la existencia del proyecto de Ley del Sistema Nacional de Emergencia y Protección Civil, el hecho de que no exista una Política Nacional de Protección Civil y que haya una falta de recursos económicos para generar mejoras reduce una incorporación efectiva del PNPC (Sanchéz, 2010), todo ello en el contexto de una ciudad con una gran necesidad de mejorar la gestión del riesgo.

\section{Conclusiones}

El diagnóstico del marco normativo sobre zonas inundables permite concluir que, pese a la existencia de varias figuras legales que delimitan áreas de alto riesgo para los asentamientos humanos, no se ha logrado una gran efectividad con respecto a la reducción del riesgo, debido a que estas áreas se delimitaron después de la construcción de todos los sectores afectados por una potencial amenaza.

El origen de la problemática se sitúa tanto en la ocupación para uso residencial de un territorio originalmente fluvial, como en la inadecuada canalización de un río que apenas tiene margen de movimiento. Por esta razón, se ha planteado una serie de alternativas relacionadas con la necesidad de devolver a la quebrada parte del territorio usurpado, siendo clave la propuesta de creación de espacios inundables que permitan laminar las crecidas de forma controlada, de tal manera que se pueda reducir el caudal aguas abajo. Junto con la ejecución de otras obras fluviales para aumentar la capacidad del cauce y la creación de nuevos instrumentos normativos de gestión del riesgo de desastres, se pretende mitigar la vulnerabilidad de la población y sus bienes ante posibles nuevas amenazas.

\section{Bibliografía}

Biblioteca del Congreso Nacional de Chile, 2014. Río Maipo. Recuperado el 27 de mayo de 2014, de http://siit2.bcn.cl/nuestropais/region13/hidrografia.htmv

Börgel, R., 1993. Vulnerabilidad y peligro de desastres en la cordillera chilena (Chile Central). Revista de Geografía Norte Grande, 20, 47-54.

Centro de Inteligencia Territorial de la Universidad Adolfo Ibáñez, 2011. Capas SIG de curvas de nivel y red hidrográfica de Chile. Santiago de Chile.

Centro de Investigación en Geografía y Geomática, 2014. Río Mapocho. Recuperado el 27 de mayo de 2014, de: http://www.centrogeo.org.mx/atlaslatinoamerica/chile/riomapocho.htm 
Concha, A., 2014. En Construcción Noticias: Parque Inundable La Aguada para Santiago de Chile. Plataforma Arquitectura. Recuperado el 4 de diciembre de 2014, de: http://www.plataforma arquitectura.cl/cl/02-75357/en-construccion-noticias-parque-inundable-la-aguada-parasantiago-de-chile

Dirección General de Aguas (DGA), 2014. Acceso a consultas en línea. Recuperado el 10 de febrero de 2014, de: http://snia.dga.cl/BNAConsultas/reportes

Dirección de Obras Hidráulicas, 2013. Obras de evacuación y drenaje de aguas lluvias. Recuperado el 24 de febrero de 2014, de http://www.doh.gob.cl/publicacionesyestudios/Documents/ Obras_de_drenaje_de_aguas_lluvias.pdf

Figueroa, J., 2000. Red Seca de Inundación: parque inundable en el suroriente de Santiago de Chile, zona de anegamientos frecuentes. Recuperado el 30 de noviembre de 2014, de: http:// www.urbanismo.8m.com/redseca/red_in.htm

García, V., 2000. Fenómenos de remociones en masa asociados a la ocurrencia de anomalías atmosféricas, Santiago Oriente. Memoria para optar al Título de Geólogo, Departamento de Geología, Universidad de Chile.

Lara Castillo, M.P., 2007. Metodología para la evaluación y zonificación de peligro de remociones en masa con aplicación en Quebrada San Ramón, Santiago Oriente, Región Metropolitana. Tesis para optar al Grado de Magíster en Ciencias, mención Geología. Memoria para optar al Título de Geólogo, Universidad de Chile, Santiago de Chile, p. 2.

Llamas, J., 1993. Hidrología general. Principios y aplicaciones. Bilbao: Servicio Editorial de la Universidad del País Vasco.

Ministerio de Obras Públicas, 1997. Ley Chile, Biblioteca del Congreso Nacional. Recuperado el 08 de diciembre de 2013, de http://www.leychile.cl/Navegar?idNorma=76725

Ministerio de Obras Públicas, 1986. Mapa hidrogeológico de Chile. Texto explicativo. Santiago de Chile: MOP.

Ministerio de Vivienda y Urbanismo, 2010. Plan Regulador Metropolitano de Santiago. Ordenanza actualizada abril 2010. Santiago de Chile: MINVU, p. 112.

Ministerio de Vivienda y Urbanismo, 1979. Política Nacional de Desarrollo Urbano. Recuperado el 28 de febrero de 2014, de http://www.minvu.cl/opensite_20061113164636.aspx

Municipalidad de La Reina, 2011. Cuenta Pública Municipal 2011. Recuperado el 20 de mayo de 2014, de http://www.lareina.cl/index.php/home/autoridades/cuenta-publica

Municipalidad de La Reina, 2014. La Reina, comunidad viva. Recuperado el 23 de febrero de 2014, de http://www.lareina.cl

Municipalidad de La Reina, 2010. Servicio de Evaluación Ambiental. Recuperado el 24 de febrero de 2014, de: https://www.e-seia.cl/archivos/TEXTO_REFUNDIDO.pdf

Municipalidad de Las Condes, 2014. Información comunal. Recuperado el 11 de junio de 2014, de http://www.lascondes.cl/informacion_comunal/portada.html

Naranjo, J.A; Varela, J., 1996. Flujos de detritos y barro que afectaron el sector oriente de Santiago el 3 de mayo de 1993. Servicio Nacional de Geología y Minería, Boletín No. 47. 
Ollero, A.; Ibisate, A.; Elso, J., 2010. El territorio fluvial. Espacio para la restauración. Notas técnicas del CIREF, ํㅡㄴ 1 .

Padilla, C., 2006. Análisis de factores meteorológicos desencadenantes de remociones en masa en el sector oriente de Santiago. Memoria para optar al Título de Geólogo, Departamento de Geología, Universidad de Chile.

Pérez Jara, M.C., 2011. Riesgo de inundación producto del cambio climático. Caso de estudio: Quebrada San Ramón. Memoria para optar al Título de Ingeniero Civil, Universidad de Chile, Santiago de Chile.

Sánchez, R., 2010. La debilidad de la gestión del riesgo en los centros urbanos. El caso del Área Metropolitana de Santiago de Chile. Revista de Geografía Norte Grande, 47, 5-26.

Stötter, J.; Zischg, A., 2008. Apines Risikomanagement-theoretische Ansätze, erste Umsetzungen. In: Felgentreff, C; Glade, T. (eds.). Naturrisiken und Sozialkatastrophen. Berlin/Heidelberg: Springer Verlag/Spektrum, p. 297-310. 